\title{
Incidence and survival of HNSCC patients living with HIV compared with HIV-negative HNSCC patients
}

\author{
Katharina Haase ${ }^{1} \cdot$ Iris Piwonski $^{2} \cdot$ Carmen Stromberger $^{3} \cdot$ Nadine Thieme $^{4} \cdot$ Max Heiland $^{5}$. \\ Benedicta Beck-Broichsitter ${ }^{5}$. Veit M. Hofmann ${ }^{6}$. Grzegorz Kofla ${ }^{7}$. Steffen Sander ${ }^{8}$. Ullrich Keilholz ${ }^{9}$. \\ Konrad Neumann $^{10} \cdot$ Katharina Stölzel $^{1} \cdot$ Heidi Olze $^{2} \cdot$ Philipp Arens $^{1} \cdot$ Steffen Dommerich ${ }^{1} \cdot$ Annekatrin Coordes ${ }^{1}$ (1)
}

Received: 7 October 2020 / Accepted: 14 December 2020 / Published online: 25 January 2021

(c) The Author(s) 2021

\begin{abstract}
Purpose The aim was to analyze the incidence and survival of patients living with HIV (PLWH) with head and neck squamous cell carcinoma (HNSCC) and to compare with a control group of HIV-negative HNSCC patients.

Methods Clinicopathological data and predictors for overall survival (OS) and disease-free survival (DFS) were investigated (2009-2019).

Results 50 of 5151 HNSCC patients $(0.97 \%)$ were PLWH, and 76\% were smokers. Age $\leq 60$ years, HIV-PCR $\leq 50$ copies, CD4 cells $\leq 200 / \mathrm{mm}^{3}$, cART treatment, T and UICC classification, oral cavity and nasal/paranasal sinuses, and therapy were significantly associated with OS in univariate analysis. In the multivariate analysis, only age and HIV-PCR independently predicted OS. The OS of the 50 PLWH was not significantly altered compared with the 5101 HIV-negative controls. However, OS and DFS were significantly inferior in advanced tumor stages of PLWH compared with an age-matched control group of $150 \mathrm{HIV}$-negative patients.

Conclusions PLWH were diagnosed with HNSCC at a significantly younger age compared to HIV-negative patients. Taking into account patient age at initial diagnosis, both OS and DFS rates in PLWH are significantly worse compared with a matched control group of HIV-negative patients in advanced tumor stages UICC III/IV. The prognosis (OS) is improved when taking cART treatment, the HIV viral load is undetectable and CD4 count is high.
\end{abstract}

Keywords HNSCC $\cdot$ HIV $\cdot$ Survival $\cdot$ Smoking $\cdot$ p16

\section{Introduction}

The prevalence of HIV infections in Germany is $0.1 \%$ [1]. HIV infections impair lymphocyte function and are therefore implicated in decreased tumor surveillance and increased cancer pathogenesis. Since the introduction of antiretroviral therapy in 1996, AIDS defining malignancies (ADMs) have declined, especially Kaposi sarcoma and non-Hodgkin lymphoma [2, 3]. HIV is now a chronic infection and people live with HIV (PLWH). However, the decrease of ADMs has been associated with an increase in non-AIDS defining

Supplementary Information The online version contains supplementary material available at https://doi.org/10.1007/s0040 5-020-06573-9.

Annekatrin Coordes

annekatrin.coordes@charite.de

Extended author information available on the last page of the article malignancies (NADMs), which include lung, anal, liver, and head and neck carcinomas [4]. Compared to the age-matched general population, NADM are more common in PLWH [5, 6]. Oncogenic viruses contribute to cancerogenesis, e.g., Human Papillomaviruses (HPV) and Epstein-Barr viruses (EBV).

Head and neck squamous cell carcinoma (HNSCC) is the sixth most common cancer worldwide with an annual global incidence of 500,000 [7, 8]. Major risk factors are excessive alcohol and tobacco consumption [9]. The proportion of smokers is higher in PLWH compared with the general population $[10,11]$. Therefore, PLWH and smokers may create an overlapping group. Another major risk factor for the development of HNSCC generally is persistent infections with high-risk HPV, especially HPV16 [12]. HPV infections are two-to-six times more common in PLWH [13]. HIV promotes the penetration of HPV viruses into the epithelium [14]. In PLWH, $40 \%$ of all malignancies are attributable to 
viral infections (compared with $4 \%$ in the general population) [15]. Thus, HPV may be an important risk factor for PLWH without a history of tobacco or alcohol consumption.

HIV is traditionally an exclusion criterion for clinical cancer trials. Therefore, a few publications are available on treatment and outcomes of PLWH and HNSCC. Picard et al. published the data of 47 Paris patients who were initially diagnosed with HNSCC between 1994 and 2014 [16]. Mourad et al. provide data of 73 New York patients with an initial HNSCC diagnosis between 1997 and 2010 [17]. Further investigations from the United States have included approximately 40 PLWH and HNSCC [18] which were compared with HIV-negative HNSCC [19-21]. Two studies including 15 and 24 PLWH and HNSCC (1995-2011 and 1985-1994) compared the survival outcomes with a control group of 3503 and 515 HIV-negative HNSCC patients [22, 23]. The French HIV study group investigated 248 patients treated in 17 centers with HNSCC (2004-2014) [24] and the North American AIDS Cohort Collaboration investigated 286 patients treated in 17 centers (1996-2009) [25].

The objective of the current study was to investigate the incidence of PLWH with HNSCC in Berlin (Germany) and to compare the long-term survival with both a control group of $5101 \mathrm{HIV}$-negative HNSCC patients and an age-matched control group of 150 patients, respectively. In addition, we investigated the impact of several clinicopathological factors on overall survival (OS) and disease-free survival (DFS) in PLWH taking into account the patient's age.

\section{Materials and methods}

\section{Patient inclusion criteria}

Following Institutional Review Board approval (appl. no.EA420117), data were reviewed from all patients with histologically confirmed head and neck malignancies (larynx, oro/naso/hypopharynx, oral cavity, and nasal/paranasal sinuses) who underwent diagnostic procedures and/or therapy at the current center between 2009 and 2019. Clinicopathological data of PLWH who developed solid HNSCC were evaluated in detail.

\section{Patient and treatment assessment}

The assessment of the 50 PLWH diagnosed with HNSCC included medical history, physical examination, serum laboratory tests, and imaging studies. A suitable control group included $150 \mathrm{HIV}$-negative HNSCC patients. Three control patients were assigned to one PLWH, taking into account the patient age ( $\pm 1-2$ years), UICC stage, and gender. According to the tumor stage and tumor site of every patient, the individual therapeutic approaches were discussed by a multidisciplinary tumor board (head and neck surgeons, medical oncologists, radiation oncologist, and head and neck radiologists), considering internationally recognized and established treatment standards. Surgical treatment required clinical in-sano resectability assessment. Neck dissection was always performed during the same procedure. All resected specimens were examined histologically. R0 resection included complete tumor removal with microscopically negative surgical margins without tumor cells. Adjuvant RT (radiotherapy) or CRT (chemoradiation) was performed in patients with advanced tumor stage (UICC $>$ II), histological evident disease (R1) or close surgical margins status, and extra capsular lymph-node spread. In locally advanced tumor stages (UICC III and IV), a definitive RT/CRT was considered as an alternative by the multidisciplinary tumor board, or the only treatment option if the tumor was deemed unresectable. The tumor stage was documented using AJCC 8th edition depending on the initial diagnosis. To investigate the impact of HPV, the surrogate marker p16 was used.

\section{Immunohistochemistry}

In all formalin fixed and paraffin-embedded tissue samples, the squamous cell carcinoma content was estimated by hematoxylin and eosin staining of the tissue sections $(2 \mu \mathrm{m})$. All samples with $<10 \%$ tumor content were excluded from p16 analysis. Immunohistochemical staining was performed using BenchMark ULTRA autostainer (Ventana, Tucson, Arizona, USA), the monoclonal rabbit antibody p16INKA4 (CINtec Histology Kit; Ventana Medical Systems, Inc.1910E. Innovation Park Drive Tucson, Arizona $85,755)$ according to the manufacturer's instructions. Overexpression of p16 was defined as medium to strong $(2+/ 3+)$ intensity of the nuclear staining with a distribution of $\geq 75 \%$ of the tumor cells.

\section{HIV diagnostics}

HIV diagnostics included PCR testing of viral load and quantitative estimation of $\mathrm{CD} 4$ and $\mathrm{CD} 8$ cells. CD4 counts and $\mathrm{CD} 4 / \mathrm{CD} 8$ ratio were used as a marker for the current integrity of the patient's immune status.

\section{Statistical analysis}

Continuous variables with normal distribution were presented as mean with standard deviation according to SAMPL Guidelines [26]. Nominal variables were expressed as number and percentage. To compare patient age, we used $\mathrm{T}$ test after controlling for normal distribution.

The primary outcomes were the incidence of HNSCC in PLWH and the OS and DFS after initial diagnosis of the HNSCC in PLWH compared with HIV-negative patients. 
OS and DFS were defined as time between the initial diagnosis of the HNSCC and the date of death or last follow-up and the date of tumor recurrence, respectively, using the Kaplan-Meier method. For univariate analyses, log-rank tests were used to assess significance.

The following clinicopathological variables were recorded and analyzed: sex (male versus female), age ( $\leq 60$ versus $>60$ years), time between initial diagnosis of HIV and initial diagnosis of HNSCC ( $<18$ versus $\geq 18$ years), history of smoking (positive versus negative), alcohol abuse (yes versus no), HIV viral load ( $\leq 50$ versus $>50$ copies), CD4 cells ( $\leq 200$ versus $>200$ copies), cART treatment (yes versus no), p16 detection (positive versus negative), additional cancers (yes versus no), $\mathrm{T}$ classification ( $\mathrm{T} 1$ versus $\mathrm{T} 2$ versus $\mathrm{T} 3$ versus $\mathrm{T} 4$ ), $\mathrm{N}$ classification (positive versus negative), UICC classification (I/II versus III/IV), tumor grading (G1 versus $\mathrm{G} 2$ versus $\mathrm{G} 3$ ), tumor site (larynx versus oral cavity versus oropharynx versus hypopharynx versus nasal/ paranasal sinuses versus nasopharynx), and tumor therapy (surgery only versus surgery + adjuvant RT/CRT versus RT/ CRT versus palliative care).

All survival-associated variables $(P<0.05)$ in the univariate analysis were further investigated using the Cox multivariate regression model with backward elimination. $P$ values $<0.05$ were considered statistically significant. Significant collinearity factors were excluded by calculating the variance inflation factor (VIF) using linear regression analysis when values were below 5. Significant differences in Cox regression were checked for normal distribution of the residuals by Schoenfeld's test. Possible influences of single unknown or missing data were assessed by additional performance of the multiple imputation model (five cycles, Mersenne twister random number generator). This revealed no relevant changes in significance parameters compared to the non-imputed data. Statistical analyses were performed using the SPSS software package, version 25.2 (SPSS, IBM Corp., Armonk, NY, USA).

\section{Results}

\section{Patient characteristics}

During the study period, 50 of 5151 HNSCC patients were PLWH $(0.97 \%)$. The clinicopathological data are summarized in Table 1 . The mean age at the initial diagnosis of HIV was 37 years (23-59 years), and the mean time between initial diagnosis of HIV and initial diagnosis of HNSCC was 18 years ( $0-35$ years). The mean age at the initial diagnosis of HNSCC in PLWH was 55 years (35-71), which was significantly less compared to the HIV-negative HNSCC patients (62 years $(29-95), p<0001) .92 \%$ of the
HNSCC PLWH were male, $76 \%$ were smokers, and $40 \%$ were drinkers.

\section{Head and neck squamous cell carcinoma}

The head and neck malignancies were located in the oropharynx $(n=19,38 \%)$, oral cavity $(n=17,34 \%)$, larynx $(n=4,8 \%)$, hypopharynx $(n=4,8 \%)$, nasopharynx $(n=2$, $4 \%$ ), and nasal/paranasal sinuses $(n=4,8 \%)$ (Fig. 1). All tumors in the HIV group were histologically confirmed squamous cell carcinoma (50/50). The majority were moderately differentiated $(n=41,82 \%)$. At the time of the initial cancer diagnosis, $34 \%$ of patients were at an early tumor stage (UICC I and II) and 66\% were advanced (UICC III and IV). Based on tumor stage, tumor resection only was performed on 17 patients. Ten patients underwent surgery followed by adjuvant treatment, definitive CRT/RT occurred in 20 patients and palliative/best supportive care in three patients. In 7 of the 24 surgically treated patients, histological evaluation revealed microscopically positive surgical margins. RT was performed with 64-72 Gy, and systemic therapy regimens included five fluorouracil and cisplatin plus/minus 5-Fluorouracil. Impaired medical conditions prevented two patients from receiving concurrent chemotherapy RT.

The control group of HIV-negative patients with HNSCC included 5101 patients spread over comparable tumor subsites and located in the oropharynx (31\%), oral cavity (36\%), larynx (18\%), hypopharynx (8\%), nasopharynx (3\%), and nasal/paranasal sinuses $(5 \%)$.

\section{HIV characteristics}

In 32 of 50 PLWH (64\%), viral load at initial diagnosis of HNSCC was not detectable. A CD 4 count $\leq 200 / \mathrm{mm}^{3}$ was observed in 18 of 50 PLWH (36\%). A CD4/CD8 ratio $<0.5 \%$ was found in 24 PLWH (48\%). 40 of 45 PLWH received cART treatment (89\%; six were unknown), which included in 14 cases HIV protease inhibitor (PI) treatment (31\%). Co-infections of hepatitis B virus (HBV) were found in 10 of 47 tested patients (21\%), hepatitis C virus (HCV) in 6 of 47 tested patients (13\%), and simultaneous $\mathrm{HBV} / \mathrm{HCV}$ in five of 47 tested patients (11\%). P16 was investigated in 38 of the 50 PLWH with HNSCC. 17 of the 38 patients were p16 positive (45\%). In PLWH and oropharynx carcinoma, 16 of 19 were investigated and 12 of the 16 patients were p16 positive $(75 \%)$.

\section{Long-term survival of PLWH}

After a median follow-up time of $20(0-211)$ months after initial cancer diagnosis in PLWH, the median survival was 40 months (95\%CI 16.0-63.9). The 1, 3, and 5 year OS rates 
Table 1 Characteristics of patients with head and neck squamous cell carcinoma living with HIV infection $(n=50)$

\begin{tabular}{|c|c|}
\hline Variable & $n=50$ \\
\hline Mean age at initial diagnosis of HNSCC, years (SD, range) & $54.64(8.275,35-71)$ \\
\hline Mean age at initial diagnosis of HIV, years (SD, range) & $37.00(9.495,23-59)$ \\
\hline $\begin{array}{l}\text { Mean time between initial diagnosis of HIV and initial diagnosis of HNSCC, years } \\
\text { (SD, range) }\end{array}$ & $17.90(8.497,0-35)$ \\
\hline Male $(\%)$ & $46(92)$ \\
\hline Smoking (\%) & $38(76)$ \\
\hline Alcohol abuse $(\%)$ & $20(40)$ \\
\hline \multicolumn{2}{|l|}{ Additional cancers $(\%)$} \\
\hline Overall & $12(24)$ \\
\hline AIDS-related & 4 \\
\hline Non-AIDS-related & 8 \\
\hline HPV-related & 1 \\
\hline \multicolumn{2}{|l|}{ HNSCC characteristics } \\
\hline \multicolumn{2}{|l|}{ Tumor site } \\
\hline Oropharynx (\%) & $19(38)$ \\
\hline Oral cavity (\%) & $17(34)$ \\
\hline Larynx $(\%)$ & $4(8)$ \\
\hline Hypopharynx (\%) & $4(8)$ \\
\hline Nasal/paranasal sinuses (\%) & $4(8)$ \\
\hline Nasopharynx (\%) & $2(4)$ \\
\hline \multicolumn{2}{|l|}{ P16 HNSCC (\%) } \\
\hline Positive & $17 / 38(45)$ \\
\hline \multicolumn{2}{|l|}{ P16 Oropharynx-Ca (\%) } \\
\hline Positive & $12 / 16(75)$ \\
\hline \multicolumn{2}{|l|}{ Grading } \\
\hline $\mathrm{G} 1(\%)$ & $2(4)$ \\
\hline $\mathrm{G} 2(\%)$ & $41(82)$ \\
\hline $\mathrm{G} 3(\%)$ & $7(14)$ \\
\hline \multicolumn{2}{|l|}{$\mathrm{T}$ classification $(\mathrm{T})$} \\
\hline $\mathrm{T} 1(\%)$ & $17(34)$ \\
\hline $\mathrm{T} 2(\%)$ & $10(20)$ \\
\hline $\mathrm{T} 3(\%)$ & $9(18)$ \\
\hline $\mathrm{T} 4(\%)$ & $14(28)$ \\
\hline \multicolumn{2}{|l|}{$\mathrm{N}$ classification $(\%)$} \\
\hline Positive & $21(42)$ \\
\hline \multicolumn{2}{|l|}{ M classification (\%) } \\
\hline Positive & $0(0)$ \\
\hline \multicolumn{2}{|l|}{ UICC } \\
\hline $\mathrm{I}(\%)$ & $12(24)$ \\
\hline II $(\%)$ & $5(10)$ \\
\hline III $(\%)$ & $8(16)$ \\
\hline IV $(\%)$ & $25(50)$ \\
\hline \multicolumn{2}{|l|}{ Therapy } \\
\hline Surgery only (\%) & $16(32)$ \\
\hline Pall. Surgery only (\%) & $1(2)$ \\
\hline Surgery + RT/CRT (\%) & $10(20)$ \\
\hline CRT $(\%)$ & $20(40)$ \\
\hline Palliative/best supportive care (\%) & $3(6)$ \\
\hline \multicolumn{2}{|l|}{ HIV characteristics } \\
\hline \multicolumn{2}{|l|}{ Viral load, HIV-PCR (\%) } \\
\hline Not detectable & $32(64)$ \\
\hline
\end{tabular}


Table 1 (continued)

\begin{tabular}{|c|c|}
\hline Variable & $n=50$ \\
\hline Median CD4 cell count (cells/ $\mu \mathrm{l})$ & $300(10-1255)$ \\
\hline Median CD8 cell count (cells/ $\mu 1)$ & $715(70-1760)$ \\
\hline \multicolumn{2}{|l|}{$\mathrm{CD} 4 / \mathrm{CD} 8$ ratio } \\
\hline$<0.5(\%)$ & $24(48)$ \\
\hline CDC Stage 1 & $0(0)$ \\
\hline CDC Stage 2 & $30(60)$ \\
\hline CDC Stage 3 & $20(40)$ \\
\hline \multicolumn{2}{|l|}{ Under cART $(\%)$} \\
\hline$(\%)$ & $40(80)$ \\
\hline \multicolumn{2}{|l|}{ Under PI (\%) } \\
\hline$(\%)$ & $14(28)$ \\
\hline \multicolumn{2}{|l|}{ Coinfection } \\
\hline $\operatorname{HBV}(\%)$ & $10(20)$ \\
\hline $\mathrm{HCV}(\%)$ & $6(12)$ \\
\hline $\mathrm{HBV}$ and $\mathrm{HCV}(\%)$ & $5(10)$ \\
\hline
\end{tabular}

$S D$ standard deviation; $A R T$ antiretroviral therapy; $P I$ protease inhibitor; $H B V$ hepatitis B virus; $H C V$ hepatitis $\mathrm{C}$ virus; $C D C$ HIV classification system of the United States Centers for Disease Control

Fig. 1 Tumor sites of the 50 patients with head and neck squamous cell carcinoma and HIV infection. The pie chart presents the proportional percentage of the tumor subsites
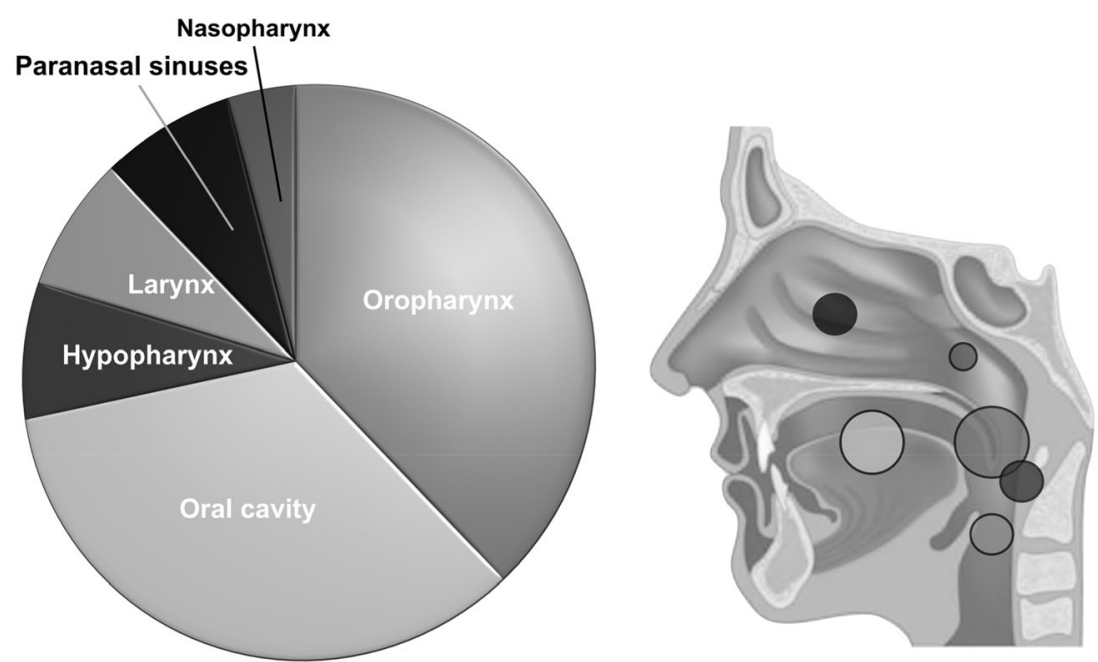

of these patients were $87.0,56.1$, and $38.4 \%$ respectively (Fig. 2A). During the follow-up period, 21 of the 50 patients died. In ten patients, the death was cancer related, and nine of those were at an advanced tumor stage (UICC III and IV) at initial diagnosis.

\section{Predictors of survival}

The results of univariate and multivariate analyses as predictors of OS and DFS for PLWH are summarized in Table 2. In univariate analysis, prognostic factors positively associated with OS included being younger than 60 at initial diagnosis of HNSCC $(p=0.005), \leq 50$ copies in HIV-PCR $(p=0.005)$, CD4 cell count $>200(p<0.001)$, under cART treatment $(p=0.005)$, early tumor stage in T classification $(p=0.006)$ and UICC classification ( $p=0.012)$, tumor sites oral cavity $(p=0.046)$, and nasal/ paranasal sinuses $(p=0.002)$ and tumor therapy (surgical treatment only vs. all other treatments, $p=0.023$ ). In the multivariate analysis, only an age of $\leq 60$ years at diagnosis and HIV-PCR $<50$ copies at initial HIV diagnosis $(\mathrm{HR}=11.58$, CI 95\% 2.06-64.92, $P=0.005)$ independently predicted OS.

P16 did not have any significant impact on OS in PLWH $(17 / 38(45 \%)$ were $\mathrm{p} 16+; p=0.645)$, even in the small subgroup of PLWH with oropharynx carcinoma (16/19 $(84 \%) ; p=0.436)$. However, in HIV-negative patients with oropharynx carcinoma, a significant effect of the p16 status on OS was observed (p16 positive: $n=269$, 

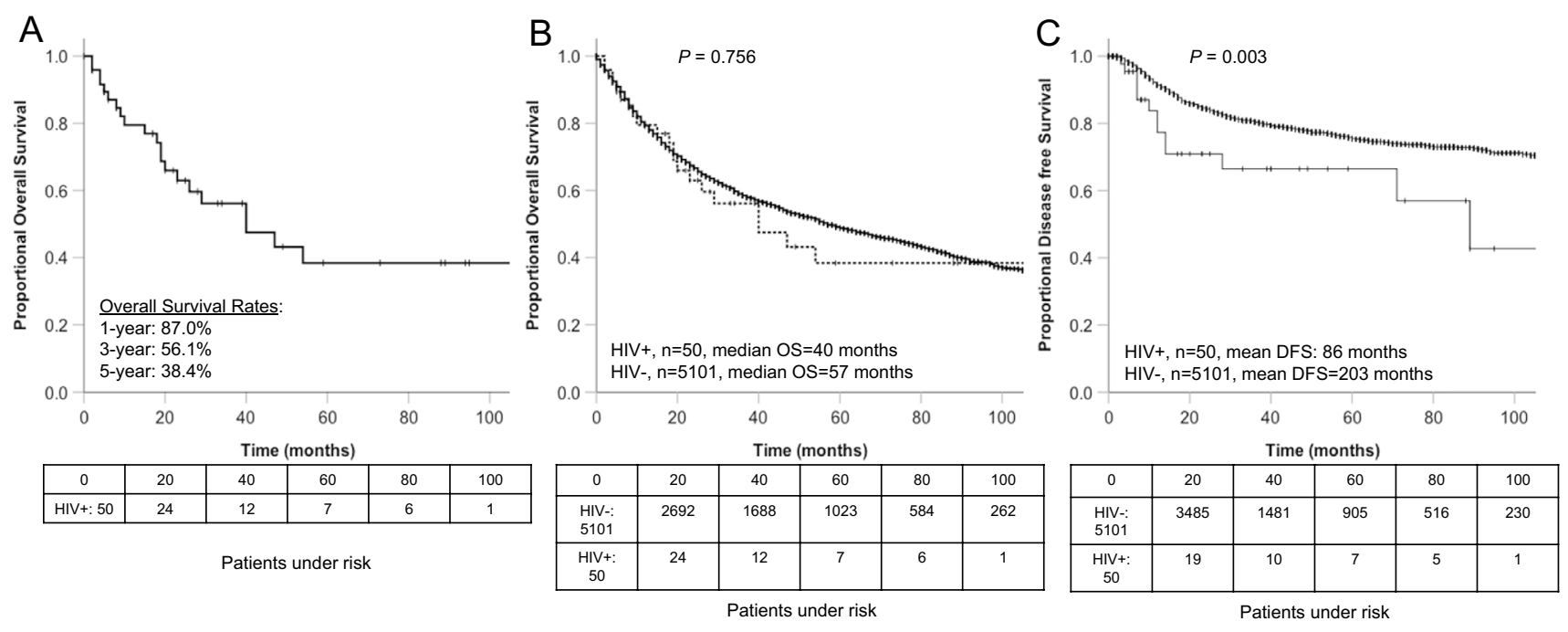

Fig. 2 Survival: a overall survival (OS) of the 50 PLWH with HNSCC. b OS of the 50 PLWH and HNSCC compared with 5101 HIV-negative patients with HNSCC. c Disease-free survival (DFS) of the 50 PLWH with HNSCC compared with 5101 HIV-negative patients with HNSCC. The boxes below the graphics show the patients at risk
meanOS: 56 months; p16 negative: $n=139$, meanOS: 50 months; $P=0.036$ ).

\section{Long-term survival of PLWH compared with controls}

The survival of HIV-negative HNSCC patients $(n=5101)$ was not significantly different (median OS 57 months, 95\% CI 52.1-61.9, $p=0.756$, Fig. 2B, Table 3). A comparable result was found for the four most common tumor subsites: oropharynx, oral cavity, larynx, and hypopharynx. Again, there was no significant difference of the OS between PLWH and HIVnegative patients (Supplementary Fig. 1). However, the DFS of PLWH was significantly diminished compared to the nonHIV population [27] ( $p=0.003$, Fig. 2c), especially in UICC III/IV $(p=0.001)$.

As we found a significant difference in patient age at initial HNSCC diagnosis in PLWH compared with HIV-negative patients, we performed an additional matched-pair analysis (1:3 match) taking into account patient age, UICC stage, and tumor site (Table 4, Supplementary Fig. 2) which significantly impacted OS in PLWH. Gender matching was considered subordinate when possible. However, it was not possible in small subgroups of less frequent sub-localisations (nasopharynx, hypopharynx, and paranasal sinuses) and in patients with tumor stage UICC I. In the matched-pair analysis, both
OS (OS for all patients: $p=0.050$; for UICC III/IV stages $p=0.010$, Fig. 3a, Table 4) and DFS (DFS for all patients: $p=0.028$; for UICC III/IV stages $p=0.010$ Fig. $3 b$, Table 4 ) were significantly reduced in PLWH.

\section{Discussion}

This study analyzed the incidence and survival of PLWH who developed HNSCC. After reviewing the data of 5151 patients with HNSCC who were treated in our center between 2009 and 2019, we identified 50 PLWH (1\%) who were diagnosed with HNSCC, $100 \%$ histologically confirmed as HNSCC.

The OS of PLWH did not significantly differ from HIVnegative patients. However, patient age at initial HNSCC diagnosis was significantly younger compared to HIV-negative HNSCC patients. Therefore, after PLWH and HNSCC were matched with a control group based on patient age, tumor site, UICC stage, and subordinated gender, a significant difference was found in both OS and DFS, each in the advanced UICC stages III/IV.

Very few studies in the literature have investigated PLWH and HNSCC. The largest cohort includes 286 and 248 patients treated in multiple centers in France and North 
Table 2 Univariate and multivariate analyses of clinicopathologic variables associated with overall survival (OS) and disease-free survival (DFS) in 50 patients with head and neck carcinoma and HIV infection

\begin{tabular}{|c|c|c|c|c|c|c|}
\hline \multirow[b]{3}{*}{ Variable } & \multirow[b]{3}{*}{$N=50$} & \multicolumn{3}{|c|}{ Overall survival (OS) } & \multirow{2}{*}{\multicolumn{2}{|c|}{$\begin{array}{l}\text { Disease free survival } \\
\text { (DFS) } \\
\text { Univariate analysis }\end{array}$}} \\
\hline & & \multicolumn{2}{|c|}{ Univariate analysis } & \multirow{2}{*}{$\begin{array}{l}\text { Multivariate analysis } \\
P, \mathrm{HR} \text { (CI 95\%) }\end{array}$} & & \\
\hline & & $\begin{array}{l}\text { Mean OS } \\
\text { (months) }\end{array}$ & $P$ & & $\begin{array}{l}\text { Mean DFS } \\
\text { (months) }\end{array}$ & $P$ \\
\hline \multicolumn{7}{|l|}{ Age (years) } \\
\hline$\leq 60$ & 39 & 99 & $\underline{0.001 \mathrm{~V}: 1.15}$ & $0.026,0.276(0.089-0.860)^{1)}$ & 90 & 0.236 \\
\hline$>60$ & 11 & 22 & & & 44 & \\
\hline \multicolumn{7}{|c|}{ Time between initial diagnosis of HIV and initial diagnosis of HNSCC (years) } \\
\hline$<18$ & 19 & 55 & 0.273 & & 86 & 0.535 \\
\hline$\geq 18$ & 21 & 55 & & & 69 & \\
\hline \multicolumn{7}{|l|}{ Sex } \\
\hline Male & 46 & 84 & 0.621 & & 89 & 0.556 \\
\hline Female & 4 & 32 & & & 31 & \\
\hline \multicolumn{7}{|l|}{ Smoking } \\
\hline Positive & 38 & 80 & 0.863 & & 89 & 0.200 \\
\hline Negative & 9 & 26 & & & 15 & \\
\hline \multicolumn{7}{|l|}{ Alcohol abuse } \\
\hline Yes & 26 & 69 & 0.967 & & 120 & $\underline{0.044}$ \\
\hline No & 20 & 48 & & & 49 & \\
\hline \multicolumn{7}{|l|}{ HIV-PCR } \\
\hline$\leq 50$ copies & 32 & 97 & $\underline{0.005 \mathrm{~V}: 1.33}$ & $0.007,6.954(1.698-28.488)^{2)}$ & 107 & 0.274 \\
\hline$>50$ copies & 18 & 33 & & & 56 & \\
\hline \multicolumn{7}{|l|}{ CD4 cells } \\
\hline$\leq 200$ & 18 & 28 & $\leq 0.001 \mathrm{~V}: 1.54$ & 0.546 & 61 & 0.615 \\
\hline$>200$ & 32 & 107 & & & 94 & \\
\hline \multicolumn{7}{|c|}{ cART treatment } \\
\hline Yes & 40 & 77 & $\underline{0.005 \mathrm{~V}: 1.44}$ & 0.906 & 97 & 0.460 \\
\hline No & 4 & 11 & & & 12 & \\
\hline \multicolumn{7}{|l|}{ PI treatment } \\
\hline Yes & 14 & 56 & 0.546 & & 42 & 0.123 \\
\hline No & 29 & 64 & & & 112 & \\
\hline \multicolumn{7}{|c|}{ P16 HNSCC (\%) } \\
\hline Positive & 17 & 44 & 0.645 & & 65 & 0.665 \\
\hline Negative & 21 & 107 & & & 71 & \\
\hline \multicolumn{7}{|c|}{ Additional cancers } \\
\hline Yes & 12 & 32 & 0.128 & & 91 & 0.263 \\
\hline No & 38 & 90 & & & 44 & \\
\hline \multicolumn{7}{|c|}{$\mathrm{T}$ classification } \\
\hline $\mathrm{T} 1$ & 17 & 120 & $\underline{0.006}$ & 0.058 & 84 & 0.852 \\
\hline $\mathrm{T} 2$ & 10 & 54 & 0.690 & & 67 & 0.539 \\
\hline $\mathrm{T} 3$ & 9 & 18 & 0.067 & & 17 & 0.572 \\
\hline $\mathrm{T} 4$ & 14 & 18 & $\underline{0.004}$ & 0.790 & 31 & 0.987 \\
\hline \multicolumn{7}{|c|}{$\mathrm{N}$ classification } \\
\hline$\geq 1$ & 21 & 50 & 0.823 & & 61 & 0.660 \\
\hline 0 & 29 & 80 & & & 92 & \\
\hline \multicolumn{7}{|l|}{ UICC } \\
\hline $\mathrm{I} / \mathrm{II}$ & 17 & 113 & $\underline{0.012 \mathrm{~V}: 4.11}$ & 0.643 & 96 & 0.570 \\
\hline III/IV & 33 & 37 & & & 60 & \\
\hline
\end{tabular}


Table 2 (continued)

\begin{tabular}{|c|c|c|c|c|c|c|}
\hline \multirow[b]{3}{*}{ Variable } & \multirow[b]{3}{*}{$N=50$} & \multicolumn{3}{|c|}{ Overall survival (OS) } & \multirow{2}{*}{\multicolumn{2}{|c|}{$\begin{array}{l}\text { Disease free survival } \\
\text { (DFS) } \\
\text { Univariate analysis }\end{array}$}} \\
\hline & & \multicolumn{2}{|c|}{ Univariate analysis } & \multirow{2}{*}{$\begin{array}{l}\text { Multivariate analysis } \\
P, \mathrm{HR} \text { (CI 95\%) }\end{array}$} & & \\
\hline & & $\begin{array}{l}\text { Mean OS } \\
\text { (months) }\end{array}$ & $P$ & & $\begin{array}{l}\text { Mean DFS } \\
\text { (months) }\end{array}$ & $P$ \\
\hline \multicolumn{7}{|l|}{ Grading } \\
\hline G1 & 2 & 19 & 0.509 & & 8 & 0.138 \\
\hline G2 & 41 & 80 & 0.855 & & 84 & 0.876 \\
\hline G3 & 7 & 55 & 0.891 & & 80 & 0.635 \\
\hline \multicolumn{7}{|l|}{ Tumor site } \\
\hline Oropharynx & 19 & 47 & 0.708 & & 65 & 0.847 \\
\hline Oral cavity & 17 & 107 & $\underline{0.046}$ & 0.650 & 86 & 0.900 \\
\hline Larynx & 4 & 22 & 0.521 & & 30 & 0.473 \\
\hline Hypopharynx & 4 & 24 & 0.806 & & 6 & 0.340 \\
\hline Nasal/paranasal sinuses & 4 & 9 & $\underline{0.002}$ & 0.599 & 13 & 0.357 \\
\hline Nasopharynx & 2 & 8 & 0.072 & & 2 & 0.705 \\
\hline \multicolumn{7}{|l|}{ Therapy } \\
\hline Only surgery & 16 & 31 & $\begin{array}{l}\frac{0.023}{\mathrm{~V}: 3.59} \\
\underline{y}\end{array}$ & 0.206 & 92 & 0.885 \\
\hline Other treatment & 34 & 17 & & & 63 & \\
\hline
\end{tabular}

Significant $\mathrm{p}$ values are underlined

$A R T$ antiretroviral therapy; PI protease inhibitor; $H N S C C$ head and neck squamous cell carcinoma; V Variance Inflation Factor

Schoenfeld's test 1) $p=0.894$; 2) $p=0.045$

Table 3 Univariate analysis of clinicopathologic variables associated with overall survival (OS) and disease-free survival (DFS) in 50 patients with head and neck malignancy and HIV infection compared to $5101 \mathrm{HIV}$-negative patients

\begin{tabular}{|c|c|c|c|c|c|c|c|c|}
\hline \multirow[t]{2}{*}{ Variable } & \multirow[b]{2}{*}{$\begin{array}{l}\mathrm{HIV+} \\
(N=50)\end{array}$} & \multirow[b]{2}{*}{$\begin{array}{l}\text { HIV- } \\
(N=5101)\end{array}$} & \multicolumn{3}{|l|}{ Overall survival } & \multicolumn{3}{|c|}{ Disease free survival } \\
\hline & & & $\begin{array}{l}\text { Mean OS } \\
\text { HIV + (months) }\end{array}$ & $\begin{array}{l}\text { Mean OS HIV- } \\
\text { (months) }\end{array}$ & $P$ & $\begin{array}{l}\text { Mean DFS } \\
\text { HIV + (months) }\end{array}$ & $\begin{array}{l}\text { Mean DFS } \\
\text { HIV-(months) }\end{array}$ & $P$ \\
\hline All patients & 50 & 5101 & 80 & 98 & 0.756 & 86 & 203 & $\underline{0.003}$ \\
\hline Female & 4 & 1413 & 32 & 86 & 0.318 & 31 & 131 & 0.111 \\
\hline Male & 46 & 3688 & 84 & 101 & 0.939 & 89 & 218 & $\underline{0.009}$ \\
\hline Smokers & 38 & 1106 & 80 & 82 & 0.681 & 89 & 106 & 0.213 \\
\hline Non-smokers & 9 & 591 & 26 & 66 & 0.522 & 15 & 73 & 0.072 \\
\hline \multicolumn{9}{|l|}{ Localization } \\
\hline Oropharynx & 19 & 1589 & 47 & 87 & 0.480 & 65 & 183 & $\underline{0.014}$ \\
\hline Oral cavity & 17 & 1840 & 84 & 107 & 0.155 & 86 & 136 & 0.087 \\
\hline Larynx & 4 & 899 & 22 & 127 & 0.231 & 30 & 216 & 0.205 \\
\hline Hypopharynx & 4 & 407 & 23 & 42 & 0.494 & n.e & n.e & 0.541 \\
\hline Paranasal sinus & 4 & 233 & 81 & 9 & $\underline{0.001}$ & 13 & 108 & 0.163 \\
\hline Nasopharynx & 2 & 133 & 88 & 8 & 0.051 & n.e & n.e & 0.920 \\
\hline $\mathrm{P} 16+$ & 17 & 374 & 44 & 58 & 0.215 & 65 & 65 & 0.518 \\
\hline P16- & 21 & 458 & 107 & 57 & 0.849 & 71 & 64 & 0.498 \\
\hline Grade 1 & 2 & 293 & 19 & 143 & 0.120 & 8 & 207 & $\underline{0.001}$ \\
\hline Grade 2 & 41 & 2690 & 80 & 87 & 0.988 & 84 & 165 & $\underline{0.013}$ \\
\hline Grade 3 & 7 & 1177 & 55 & 73 & 0.870 & 80 & 134 & 0.618 \\
\hline UICC I/II & 17 & 827 & 113 & 124 & 0.617 & 147 & 174 & 0.504 \\
\hline UICC III/IV & 33 & 2410 & 37 & 65 & 0.652 & 60 & 158 & $\underline{0.001}$ \\
\hline
\end{tabular}

Significant $\mathrm{p}$ values are underlined 


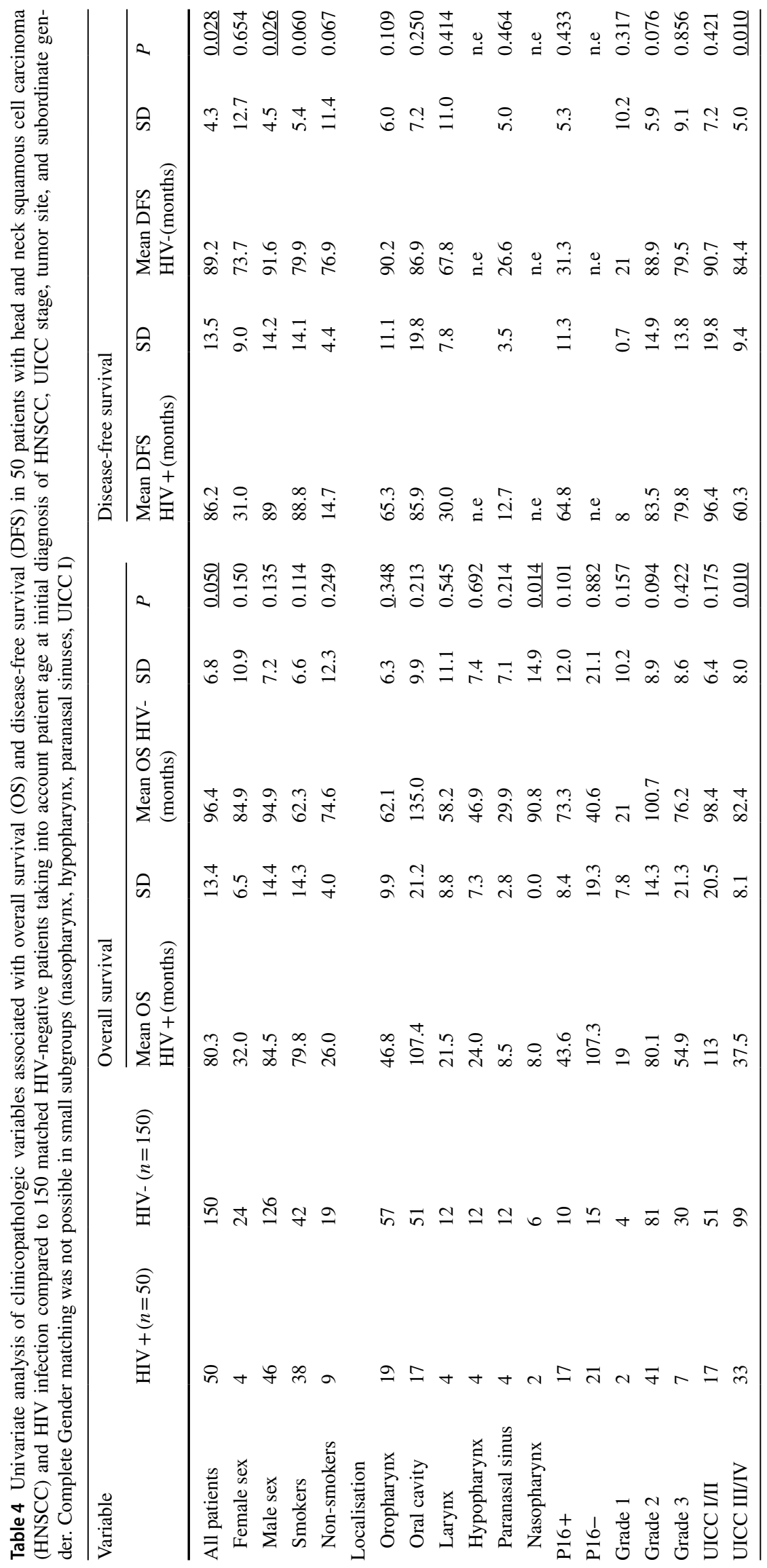




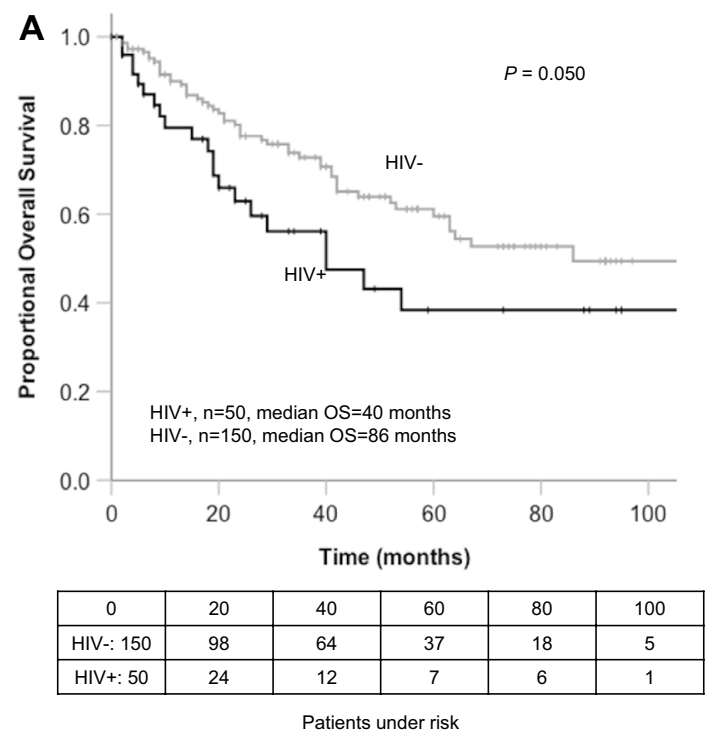

Fig. 3 Survival compared to an age-matched control group. Overall survival (a) and disease-free survival (b) of the 50 PLWH and HNSCC compared with a matched control group of 150 HNSCC

America, respectively, without an HIV-negative control group comparison $[24,25]$. Two smaller studies including 15 and 24 PLWH and HNSCC compared survival with an HIV-negative control group [22, 23]. The current study is the largest monocenter study of PLWH 10 years after cART therapy. It compared survival rates with HIV-negative patients according to sub-localization and tumor stage, and it compared PLWH and HNSCC with a matched control group taking in account patient age, UICC stage, tumor site, and gender.

The characteristics of the patients included in this study were comparable with those of PLWH in previous studies reporting on HNSCC. 92\% were males, mean time between initial HIV diagnosis and initial HNSCC diagnosis was 17.9 years [16], and the mean age at initial HNSCC diagnosis was significantly earlier compared to HIV-negative patients $[4,16]$. The most frequent tumor sites were oropharynx (38.0\%) and oral cavity (34.0\%) [16]. Two older studies found the larynx to be the most frequent subsite [22, 28]. In the current study, $76 \%$ were smokers and $49 \%$ had a history of alcohol abuse. PLWH have an increased risk profile developing HNSCC. PLWH smoke more often compared with the general population and have greater difficulty quitting smoking $[10,11]$. Therefore, PLWH with high-risk TP53 mutations have poor survival outcomes and the fastest development of distant metastases [20,21]. Another major risk factor for the HNSCC pathogenesis are persistent infections with high-risk HPV, especially HPV16 $[12,23]$. In PLWH and HNSCC, the heterogeneity of HPV subtypes is higher [16, 20]. In the general population, persistent HPV infections may cause $25 \%$ of

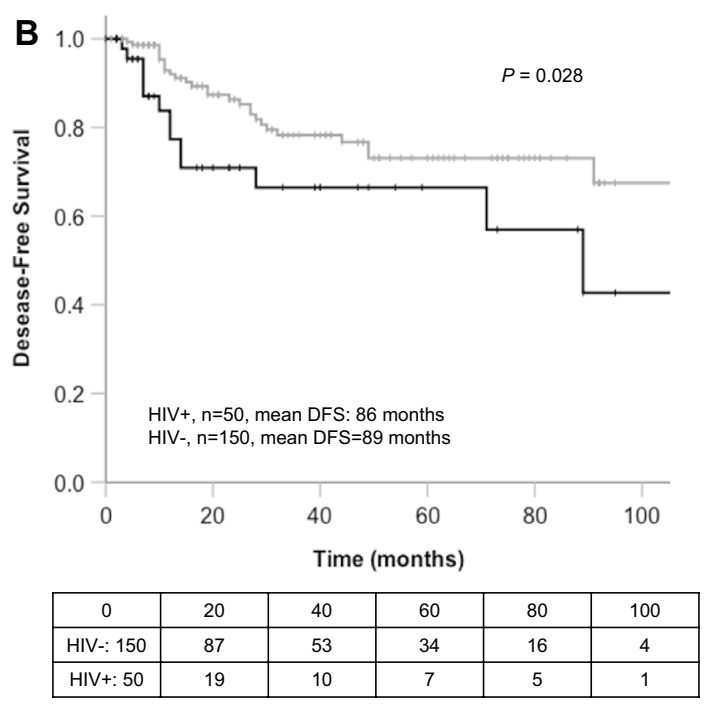

Patients under risk

patients taking in account patient age, UICC stage, tumor site, and subordinate gender (Supplementary Fig. 2, Table 4)

HNSCC and up to $75 \%$ of oropharyngeal cancer [12]. Longterm immunosuppression increases the risk of malignancies associated with oncogenic viral infections. Ceccarelli et al. systematically investigated the correlation of HPV and HIV in HNSCC patients [29]. In the current study, p16 did not have a significant impact on OS in PLWH $(p=0.645)$ and in the small subgroup of PLWH with oropharynx carcinoma $(p=0.436)$. However, 16 out of 19 patients $(84 \%)$ had $\mathrm{p} 16$ positive oropharynx carcinoma and it is reasonable to assume that HPV contributes to the development of oropharynx carcinoma in PLWH. The p16 negative group was probably too small to show statistical significance. In HIV-negative patients with oropharynx carcinoma, p16 was associated with significantly improved OS $(p=0.036)$ which is consistent with the literature [30-32]. Therefore, the 8th edition of UICC presented a different tumor staging depending on the detection of p16. This classification does not consider smoking habits. In PLWH with p16 positive oropharynx carcinoma who are smokers, survival classified by the risk of death score proposed by Ang et al. [33] (which is based on HPV status and smoking history) may provide a better correlation. In the current study, 10 of 29 (35\%) PLWH had p16 positive HNSCC and were smokers, and seven of ten $(70 \%)$ had oropharyngeal carcinoma. Additionally, current smokers have significantly higher HPV infections [34].

In PLWH, HNSCC are more frequent compared to the general population. Beachler et al. [25] found a threefold increased incidence of HNSCC in PLWH and Robbins et al. found a doubled incidence in oral cavity and pharyngeal carcinoma in PLWH in the United States [35]. In the current 
study, we found a tenfold increased prevalence of HIV in HNSCC patients compared to the general population [1].

In the current study, the treatment strategies depended on the UICC stage (Supplementary Fig. 1). 85\% of patients in the current study with advanced tumors (UICC III and IV) were treated with resection combined with adjuvant RT/ CRT or primary RT/CRT only, whereas $88 \%$ of patients at an early tumor stage (UICC I and II) underwent resection only. Patients eligible for surgery only had a significantly improved OS compared to patients whose tumor stage required surgery combined with adjuvant RT/CRT or primary RT/CRT $(P=0.023)$. The latter two therapeutic options did not reveal a significant difference in OS $(P=0.278)$.

Picard et al., who investigated PLWH between 1997 and 2010 in New York, concluded that PLWH have worse OS and DFS undergoing definitive R(C)T compared with HIVnegative HNSCC patients [17]. The poorer outcomes in both OS and DFS in PLWH with advanced tumor stages which require adjuvant or primary RT/CRT could be explained by the fact that long-term immunosuppression by the virus may impair the therapeutic treatment's action [36, 37].

In addition to the increased risk profile of many HIV patients for HNSCC, recent work from the United States has shown that PLWH have a distinct HNSCC mutation pattern [38]. Oncogenic HIV may also promote its own pathogenesis of HNSCC which is attributed to the HIV transactivator protein tat which stimulates the cell cycle and inhibits apoptosis [39]. Additionally, tat upregulates the expression of the oncoproteins E6 and E7 [40]. This may explain the results of cohort studies which showed that HIV infection may increase lung cancer risk after adjusting for tobacco and other confounders [41, 42].

In the current study, patients with $>50$ copies of HIVPCR $(p=0.005)$ and a CD4 cell count $\leq 200$ cells $/ \mathrm{mm}^{3}$ had a significantly poorer prognosis $(p<0.001)$. A low number of CD4 + T lymphocytes may support the carcinogenesis of HNSCC [25] and may be associated with poor prognosis [19]. Other groups showed HPV-positive status was associated with a CD4 + nadir of $<200$, but not with CD4 + level at time of diagnosis [16].

Immune checkpoint inhibitors are promising cancer therapies. In PLWH, very little experience is available at present. An ongoing trial is evaluating pembrolizumab in PLWH and a variety of metastatic cancers. Inclusion criteria are having a CD4 + T-cell count of $>200$ (NCT02595866). However, HIV is no contraindication for treatment with anti PD-1. Patients with HIV/AIDS and low CD4 + T-cell counts should be monitored closely [43]. Liu et al. have shown that HIV PI sensitize HNSCC cells to radiotherapy by activation of endoplasmic reticulum stress and induction of an immunogenic cell death. Therefore, HIV PIs may be potentially used in combination with radiation in the treatment of HNSCC [44]. In the current study, cART treatment had a significant impact on OS, while the application of HIV PIs in $31 \%$ did not alter OS. However, only $7 / 14$ patients with cART and HIV PIs underwent definitive or adjuvant (C)RT. Therefore, further investigations are necessary. By triggering the immunogenic cell death, the PI therapy could also increase the effect of the immune checkpoint inhibitors.

Our current study of PLWH who developed HNSCC has some limitations. Given the rarity of this disease in PLWH ( 50 of 5151 patients, $0.97 \%$ ), compiling a cohort large enough to facilitate prognostic factor analysis (see Table 4) would require including patients from an even longer time period or comparing multiple centers including a control group of HIV-negative HNSCC patients.

\section{Conclusion}

PLWH were diagnosed with HNSCC at a significantly younger age compared to HIV-negative patients. Taking into account patient age at initial diagnosis, both OS and DFS rates in PLWH are significantly worse compared with a matched control group of HIV-negative patients in advanced tumor stages UICC III/IV. The prognosis (OS) is improved when taking cART treatment, the HIV viral load is undetectable and CD4 count is high.

\section{Acknowledgments None.}

Funding Open Access funding enabled and organized by Projekt DEAL.

Data availability All relevant data are transparent presented, supplemental figures include additional information of the patient cohort and the matched group.

Code availability SPSS software package, version 25.2 (SPSS, IBM Corp., Armonk, NY, USA).

\section{Compliance with ethical standards}

Conflict of interest Ullrich Keilholz: COI statement is deposited at the Publisher, Philipp Arens: financial support from ImThera Inc. and Apnex Medical Inc. for sleep research studies; lecture fee from Inspire Medical Inc.

Ethical approval The manuscript has been seen and approved by all contributing authors, it is not under active consideration for publication, has not been accepted for publication, nor has it been published, in full or in part.

Open Access This article is licensed under a Creative Commons Attribution 4.0 International License, which permits use, sharing, adaptation, distribution and reproduction in any medium or format, as long as you give appropriate credit to the original author(s) and the source, provide a link to the Creative Commons licence, and indicate if changes were made. The images or other third party material in this article are 
included in the article's Creative Commons licence, unless indicated otherwise in a credit line to the material. If material is not included in the article's Creative Commons licence and your intended use is not permitted by statutory regulation or exceeds the permitted use, you will need to obtain permission directly from the copyright holder. To view a copy of this licence, visit http://creativecommons.org/licenses/by/4.0/.

\section{References}

1. Robert Koch Institut Germany. Estimation of the number of new HIV infections and the total number of people with HIV in Germany, as of the end of 2018. Epidemiologisches Bulletin 2019;46 [published Online First: 24.01.2020]

2. Polesel J, Clifford GM, Rickenbach M et al (2008) Non-Hodgkin lymphoma incidence in the Swiss HIV Cohort Study before and after highly active antiretroviral therapy. AIDS 22(2):301-306. https://doi.org/10.1097/QAD.0b013e3282f2705d

3. Franceschi S, Maso LD, Rickenbach M et al (2008) Kaposi sarcoma incidence in the Swiss HIV Cohort Study before and after highly active antiretroviral therapy. Br J Cancer 99(5):800-804. https://doi.org/10.1038/sj.bjc.6604520

4. Brickman C, Palefsky JM (2015) Cancer in the HIV-infected host: epidemiology and pathogenesis in the antiretroviral era. Curr HIV/AIDS Rep 12(4):388-396. https://doi.org/10.1007/s1190 4-015-0283-7

5. Morlat P, Roussillon C, Henard S et al (2014) Causes of death among HIV-infected patients in France in 2010 (national survey): trends since 2000. AIDS 28(8):1181-1191. https://doi. org/10.1097/QAD.0000000000000222

6. Robbins HA, Pfeiffer RM, Shiels MS et al (2015) Excess cancers among HIV-infected people in the United States. J Natl Cancer Inst. https://doi.org/10.1093/jnci/dju503

7. Kamangar F, Dores GM, Anderson WF (2006) Patterns of cancer incidence, mortality, and prevalence across five continents: defining priorities to reduce cancer disparities in different geographic regions of the world. J Clin Oncol 24(14):2137-2150

8. Parkin DM, Bray F, Ferlay J et al (2005) Global cancer statistics, 2002. CA Cancer J Clin 55(2):74-108

9. Blot WJ, McLaughlin JK, Winn DM et al (1988) Smoking and drinking in relation to oral and pharyngeal cancer. Cancer Res 48(11):3282-3287 (published Online First: 1988/06/01)

10. Mdodo R, Frazier EL, Dube SR et al (2015) Cigarette smoking prevalence among adults with HIV compared with the general adult population in the United States: cross-sectional surveys. Ann Intern Med 162(5):335-344. https://doi.org/10.7326/M14-0954

11. Gritz ER, Vidrine DJ, Lazev AB et al (2004) Smoking behavior in a low-income multiethnic HIV/AIDS population. Nicotine Tob Res 6(1):71-77. https://doi.org/10.1080/14622200310001656885

12. Kreimer AR, Clifford GM, Boyle P et al (2005) Human papillomavirus types in head and neck squamous cell carcinomas worldwide: a systematic review. Cancer Epidemiol Biomarkers Prev 14(2):467-475

13. Anaya-Saavedra G, Flores-Moreno B, Garcia-Carranca A et al (2013) HPV oral lesions in HIV-infected patients: the impact of long-term HAART. J Oral Pathol Med 42(6):443-449. https://doi. org/10.1111/jop.12032 (publishedOnlineFirst:2013/01/03)

14. Tugizov SM, Webster-Cyriaque JY, Syrianen S et al (2011) Mechanisms of viral infections associated with HIV: workshop 2B. Adv Dent Res 23(1):130-136. https://doi.org/10.1177/00220 34511400076 (publishedOnlineFirst:2011/03/29)

15. de Martel C, Shiels MS, Franceschi S et al (2015) Cancers attributable to infections among adults with HIV in the United States.
AIDS 29(16):2173-2181. https://doi.org/10.1097/QAD.00000 00000000808

16. Picard A, Badoual C, Hourseau M et al (2016) Human papilloma virus prevalence in HIV patients with head and neck squamous cell carcinoma. AIDS 30(8):1257-1266. https://doi.org/10.1097/ QAD.0000000000001030

17. Mourad WF, Hu KS, Ishihara D et al (2013) Tolerance and toxicity of primary radiation therapy in the management of seropositive HIV patients with squamous cell carcinoma of the head and neck. Laryngoscope 123(5):1178-1183. https://doi.org/10.1002/ lary. 23874

18. McLemore MS, Haigentz M Jr, Smith RV et al (2010) Head and neck squamous cell carcinomas in HIV-positive patients: a preliminary investigation of viral associations. Head Neck Pathol 4(2):97-105. https://doi.org/10.1007/s12105-010-0171-9

19. Zhang H, Kim S, Chen Z et al (2017) Prognostic biomarkers in patients with human immunodeficiency virus-positive disease with head and neck squamous cell carcinoma. Head Neck 39(12):2433-2443. https://doi.org/10.1002/hed.24911

20. Walline HM, Carey TE, Goudsmit CM et al (2017) High-risk HPV, biomarkers, and outcome in matched cohorts of head and neck cancer patients positive and negative for HIV. Mol Cancer Res 15(2):179-188. https://doi.org/10.1158/1541-7786. MCR-16-0255

21. Neskey DM, Osman AA, Ow TJ et al (2015) Evolutionary action score of TP53 identifies high-risk mutations associated with decreased survival and increased distant metastases in head and neck cancer. Cancer Res 75(7):1527-1536. https://doi. org/10.1158/0008-5472.CAN-14-2735

22. Singh B, Balwally AN, Shaha AR et al (1996) Upper aerodigestive tract squamous cell carcinoma. The human immunodeficiency virus connection. Arch Otolaryngol Head Neck Surg 122(6):639-643

23. Helleberg M, Gerstoft J, Afzal S et al (2014) Risk of cancer among HIV-infected individuals compared to the background population: impact of smoking and HIV. AIDS 28(10):1499-1508. https://doi. org/10.1097/QAD.0000000000000283

24. Picard A, Arowas L, Piroth L et al (2018) Head and neck squamous cell carcinoma in people living with HIV in France. Med Mal Infect 48(8):503-508. https://doi.org/10.1016/j.medma 1.2018.05.002 (publishedOnlineFirst:2018/06/12)

25. Beachler DC, Abraham AG, Silverberg MJ et al (2014) Incidence and risk factors of HPV-related and HPV-unrelated Head and Neck Squamous Cell Carcinoma in HIV-infected individuals. Oral Oncol 50(12):1169-1176. https://doi.org/10.1016/j.oralo ncology.2014.09.011 (publishedOnlineFirst:2014/10/11)

26. Smart P, Maisonneuve H, Polderman A (2013) The SAMPL guidelines. Science editors' handbook, European Association of Science Editors. https://www.equator-network.org/wp-content/ uploads/2013/03/SAMPL-Guidelines-3-13-13.pdf

27. CommonGermanCancerRegistryOfTheNewFederalGermanStatesAndBerlin. Gemeinsames Krebsregister - Krebsinzidenz und Krebsmortalität 2007-2008 (annual report). Berlin, Germany, $1 / 2012$.

28. Mourad WF, Hu KS, Shasha D et al (2013) Long-term outcome of seropositive HIV patients with head and neck squamous cell carcinoma treated with radiation therapy and chemotherapy. Anticancer Res 33(12):5511-5516

29. Ceccarelli M, Rullo EV, Facciola A et al (2018) Head and neck squamous cell carcinoma and its correlation with human papillomavirus in people living with HIV: a systematic review. Oncotarget 9(24):17171-17180. https://doi.org/10.18632/oncotarget .24660 (publishedOnlineFirst:2018/04/24)

30. Lassen P, Eriksen JG, Krogdahl A et al (2011) The influence of HPV-associated p16-expression on accelerated fractionated 
radiotherapy in head and neck cancer: evaluation of the randomised DAHANCA $6 \& 7$ trial. Radiother Oncol 100(1):49-55

31. Fischer CA, Kampmann M, Zlobec I et al (2010) p16 expression in oropharyngeal cancer: its impact on staging and prognosis compared with the conventional clinical staging parameters. Ann Oncol 21(10):1961-1966

32. Dayyani F, Etzel CJ, Liu M et al (2010) Meta-analysis of the impact of human papillomavirus (HPV) on cancer risk and overall survival in head and neck squamous cell carcinomas (HNSCC). Head Neck Oncol 2:15

33. Ang KK, Harris J, Wheeler R et al (2010) Human papillomavirus and survival of patients with oropharyngeal cancer. New Eng J Med 363(1):24-35. https://doi.org/10.1056/NEJMoa0912217 (publishedOnlineFirst:2010/06/10)

34. Schabath MB, Villa LL, Lin HY et al (2014) A prospective analysis of smoking and human papillomavirus infection among men in the HPV in Men Study. Int J Cancer 134(10):2448-2457. https ://doi.org/10.1002/ijc. 28567

35. Robbins HA, Engels EA et al (2015) Excess cancers among HIVinfected people in the United States. JNCI 107(4):1-8. https://doi. org/10.1093/jnci/dju503

36. Shibuya TY, Nugyen N, McLaren CE et al (2002) Clinical significance of poor CD3 response in head and neck cancer. Clin Cancer Res 8(3):745-751

37. Uemura T, Riley TR, Khan A et al (2011) Immune functional assay for immunosuppressive management in post-transplant malignancy. Clin Transplant 25(1):E32-E37

38. Gleber-Netto FO, Zhao M, Trivedi S et al (2018) Distinct pattern of TP53 mutations in human immunodeficiency virus-related head and neck squamous cell carcinoma. Cancer 124(1):84-94. https:// doi.org/10.1002/cncr.31063
39. Romani B, Glashoff RH, Engelbrecht S (2010) Functional integrity of naturally occurring mutants of HIV-1 subtype C Vpr. Virus Res 153(2):288-298. https://doi.org/10.1016/j.virus res.2010.08.020

40. Kim RH, Yochim JM, Kang MK et al (2008) HIV-1 Tat enhances replicative potential of human oral keratinocytes harboring HPV16 genome. Int J Oncol 33(4):777-782

41. Kirk GD, Merlo C, O'Driscoll P et al (2007) HIV infection is associated with an increased risk for lung cancer, independent of smoking. Clin Infect Dis 45(1):103-110. https://doi. org/10.1086/518606

42. Engels EA, Brock MV, Chen J et al (2006) Elevated incidence of lung cancer among HIV-infected individuals. J Clin Oncol 24(9):1383-1388. https://doi.org/10.1200/JCO.2005.03.4413

43. Johnson DB, Sullivan RJ, Menzies AM (2017) Immune checkpoint inhibitors in challenging populations. Cancer 123(11):1904 1911. https://doi.org/10.1002/cncr.30642[publishedOnlineFirst :2017/02/28]

44. Liu R, Zhang L, Yang J et al (2015) HIV Protease Inhibitors Sensitize Human Head and Neck Squamous Carcinoma Cells to Radiation by Activating Endoplasmic Reticulum Stress. PLoS ONE 10(5):e0125928. https://doi.org/10.1371/journal.pone.01259 28[publishedOnlineFirst:2015/05/02]

Publisher's Note Springer Nature remains neutral with regard to jurisdictional claims in published maps and institutional affiliations.

\section{Authors and Affiliations}

\section{Katharina Haase ${ }^{1} \cdot$ Iris Piwonski ${ }^{2}$. Carmen Stromberger ${ }^{3} \cdot$ Nadine Thieme $^{4} \cdot$ Max Heiland $^{5}$. Benedicta Beck-Broichsitter ${ }^{5}$. Veit M. Hofmann ${ }^{6}$. Grzegorz Kofla ${ }^{7}$. Steffen Sander ${ }^{8}$. Ullrich Keilholz ${ }^{9}$. Konrad Neumann $^{10} \cdot$ Katharina Stölzel $^{1} \cdot$ Heidi Olze $^{2} \cdot$ Philipp Arens $^{1} \cdot$ Steffen Dommerich ${ }^{1} \cdot$ Annekatrin Coordes ${ }^{1}$ (1)}

1 Department of Otorhinolaryngology, Head and Neck Surgery, Charité-Universitätsmedizin Berlin, corporate member of Freie Universität Berlin, Humboldt-Universität $\mathrm{Zu}$ Berlin, and Berlin Institute of Health, Campus Virchow Klinikum and Campus Charité Mitte, Augustenburger Platz 1, 13353 Berlin, Germany

2 Department of Pathology, Charité-Universitätsmedizin Berlin, corporate member of Freie Universität Berlin, Humboldt-Universität $\mathrm{Zu}$ Berlin, and Berlin Institute of Health, Berlin, Germany

3 Department of Radiooncology, Charité-Universitätsmedizin Berlin, corporate member of Freie Universität Berlin, Humboldt-Universität Zu Berlin, and Berlin Institute of Health, Campus Virchow Klinikum, Berlin, Germany

4 Department of Radiology, Charité-Universitätsmedizin Berlin, corporate member of Freie Universität Berlin, Humboldt-Universität $\mathrm{Zu}$ Berlin, and Berlin Institute of Health, Campus Virchow Klinikum, Berlin, Germany

5 Department of Oral and Maxillofacial Surgery, CharitéUniversitätsmedizin Berlin, corporate member of Freie Universität Berlin, Humboldt-Universität Zu Berlin, and Berlin Institute of Health, Campus Virchow Klinikum and Campus Benjamin Franklin, Berlin, Germany
6 Department of Otorhinolaryngology, Head and Neck Surgery, Charité-Universitätsmedizin Berlin, corporate member of Freie Universität Berlin, Humboldt-Universität $\mathrm{Zu}$ Berlin, and Berlin Institute of Health, Campus Benjamin Franklin, Berlin, Germany

7 Department of Oncology, Charité-Universitätsmedizin Berlin, corporate member of Freie Universität Berlin, Humboldt-Universität Zu Berlin, and Berlin Institute of Health, Campus Virchow Klinikum, Berlin, Germany

8 Clinical Cancer Registry, Charité Comprehensive Center (CCCC), Charité-Universitätsmedizin Berlin, corporate member of Freie Universität Berlin, Humboldt-Universität Zu Berlin, and Berlin Institute of Health, Campus Charité Mitte, Berlin, Germany

9 Department of Oncology, Charité-Universitätsmedizin Berlin, corporate member of Freie Universität Berlin, Humboldt-Universität Zu Berlin, and Berlin Institute of Health, Campus Benjamin Franklin, Berlin, Germany

10 Institute for Biometrics and Clinical Epidemiology, Charité-Universitätsmedizin Berlin, corporate member of Freie Universität Berlin, Humboldt-Universität Zu Berlin, and Berlin Institute of Health, Campus Charite Mitte, Berlin, Germany 